\title{
Preventive effect of total flavonoids of Trollius altaicus on a chronic obstructive pulmonary disease rat model based on the TLR4/NF-кB pathway
}

\author{
Yatan $\mathrm{Li}^{1}$, Jun $\mathrm{Zhao}^{2}$, Hua Shao ${ }^{3}$, Wei Jia ${ }^{4}$, Deqi Su${ }^{1}$, Tao Liu ${ }^{1}$ \\ ${ }^{1}$ Department of Toxicology, School of Public Health, Xinjiang Medical University, Urumqi, China; ${ }^{2}$ Key Laboratory for Uighur Medicine, Institute \\ of Materia Medica of Xinjiang, Urumqi, China; ${ }^{3}$ Imaging Center, The First Affiliated Hospital of Xinjiang Medical University, Urumqi, China; \\ ${ }^{4}$ Department of Infection Management, Tumor Hospital Affiliated to Xinjiang Medical University, Urumqi, China \\ Contributions: (I) Conception and design: T Liu, J Zhao; (II) Administrative support: Y Li; (III) Provision of study materials or patients: D Su; (IV) \\ Collection and assembly of data: Y Li, H Shao; (V) Data analysis and interpretation: Y Li, W Jia; (VI) Manuscript writing: All authors; (VII) Final \\ approval of manuscript: All authors. \\ Correspondence to: Tao Liu. Department of Toxicology, School of Public Health, Xinjiang Medical University, Urumqi 830011, China. \\ Email: xjmult@163.com.
}

Background: Chronic obstructive pulmonary disease (COPD) is diagnosed based on the clinical symptoms, risk factors, and pulmonary function tests. Exposure to cigarette smoke (CS), microbial infection stimulates monocytes and macrophages to rapidly synthesise and release inflammatory factors. A previous study of Trollius altaicus (TAF) revealed that it had significant anti-inflammatory and anti-oxidation effects on a pneumonia disease. Based on recent studies of the inflammatory pathway of toll-like receptor 4 (TLR4)/ nuclear factor kappa B (NF-kB), we will explore the influence of TAF on COPD.

Methods: Wistar rats were randomly divided into blank control group, Model Group, low-dose TAF + model group, middle-dose TAF + model group, high-dose TAF + model group, positive control + model group. Except for the blank control group, COPD inflammation models were established in all groups by CS poisoning and LPS. Prior to the daily poisoning, $125 \mathrm{mg} / \mathrm{kg}, 250 \mathrm{mg} / \mathrm{kg}$, and $500 \mathrm{mg} / \mathrm{kg}$ of TAF were administered by gavage in the low-, middle-, and high-dose groups, respectively, and dexamethasone solution ( $1 \mathrm{mg} / \mathrm{kg}$, once daily) was administered continuously in the positive control group on the last 5 days of modelling. General signs, lung function indices, lung imaging results, complete blood count, lung histopathological changes, inflammatory factors in the alveolar lavage fluid, relative expressions of TLR4, I $\kappa$ B kinase $\alpha(\mathrm{IKK} \alpha)$, p65, as well as IL-1 $\beta$ proteins and their mRNA relative expressions were measured and compared between each group.

Results: Compared with the blank control group, TAF effectively reduced pulmonary parenchymal oedema (wet-to-dry ratio) and respiratory secretions. It also significantly delayed lung function injury. Lung X-ray imaging and haematoxylin and eosin staining. Blood routine examination results showed that TAF effectively inhibited the increase of white blood cell, lymphocyte, and eosinophil counts, decreased the release of inflammatory cytokines [IL-1 $\beta$, IL-6, IL-8, TNF- $\alpha$, and transforming growth factor- $1 \beta$ (TGF-1 $\beta$ )] and promoted the release of IL-10. It also inhibited the relative expressions of TLR4, IKK $\alpha$, p65, IL-1 $\beta$ proteins, as well as IL-1 receptor-associated kinase (IRAK-1), IKKa, p65, and IL-1 $\beta$ mRNA.

Conclusions: Early intervention of TAF can reduce the occurrence of COPD, reduce the development of inflammation via TLR/NF- $\kappa$ B pathway, and provide reference for further study of the medicinal value of TAF.

Keywords: Air inflammatory; chronic obstructive pulmonary disease (COPD); preventive effect; TLR4/ NF- $\mathrm{BB}$; total flavonoids of Trollius altaicus (TAF) 
Submitted Dec 17, 2021. Accepted for publication Feb 21, 2022.

doi: 10.21037/atm-22-331

View this article at: https://dx.doi.org/10.21037/atm-22-331

\section{Introduction}

Chronic obstructive pulmonary disease (COPD), a chronic respiratory disease characterised by persistent cough, sputum production, wheezing, and incomplete reversible airflow limitation, is a leading cause of respiratory diseaserelated morbidity and mortality worldwide $(1,2)$. The Global Initiative on Chronic Lung Disease (referred to as GOLD, as revised in 2020) defines COPD as a common, preventable, and treatable disease $(3,4)$. Smoking and infection are major risk factors of COPD (5). Given its high recurrence and progressive exacerbation, COPD is estimated to pose a heavy disease burden on the families of patients as well as society. Therefore, preventing the occurrence and development of COPD has become an important public health issue (6).

The clinical diagnostic criteria for COPD include clinical symptoms, risk factors, and pulmonary function. Exposure to cigarette smoke (CS), air pollution, or microbial infection stimulates monocytes, macrophages, and granulocytes to rapidly synthesise and release tumour necrosis factor (TNF)- $\alpha$ and interleukin (IL)-8. The systemic inflammatory response can increase the levels of pro-inflammatory factors, such as IL- $\beta 1$, IL- 6 , and TNF- $\alpha$, in patients with COPD 2-4 times (7). Furthermore, the neutrophil to lymphocyte ratio in peripheral blood is significantly increased in patients with stable or acute exacerbation COPD, and the eosinophil granulocyte level, pulmonary function, and inflammatory factors also affect the establishment of a specific reference value (8). Among the signalling pathways related to the pathogenesis of COPD, the NF- $\kappa \mathrm{B}$ pathway is closely related to the occurrence and development of lung inflammation. The classical pathways can be activated by TNF, IL-1, and lipopolysaccharide (LPS), which promote the spread of inflammation, and LPS can also weakly activate non-classical pathways (9).

Trollius chinensis Bunge is a herbaceous plant of the genus Ranunculaceae, and was first recorded in 'Compendium of Materia Medica' (10). Modern pharmaceutical research and clinical application has revealed that it has antibacterial, antiviral, and anti-tumour properties (11). Trollius altaicus of Trollius chinensis Bunge is a characteristic medicinal plant of Kazakh medicine in Xinjiang, China. Our research group has successfully extracted its main active ingredient-total flavonoids of Trollius altaicus (TAF) $(12,13)$. Previous studies have evaluated the anti-inflammatory and antioxidant effects of TAF on acute lung injury and pulmonary fibrosis in rats and cough in mice (14-17) and its effective inhibition of Streptococcus mutans (18). Furthermore, the antiinflammatory effect of TAF on an acute lung injury cell model was verified by comparing the expression levels of ІкB kinase $\alpha(\mathrm{IKKa})$ and p65 mRNA in the NF- $\mathrm{kB}$ pathway (19). Although there have been many studies on COPD and its mechanism includes anti-inframammary, no article had shown TAF's effect and mechanism to COPD. our research ought to confirm it.

Combined with the main characteristics of COPD diagnosis and previous studies of our research group, this study aimed to establish a COPD rat model through the combined exposure of CS and LPS (20), using TAF as an early drug intervention to study whether it can delay COPD development and reduce inflammatory lesions under normal conditions. We also aimed to investigate its mechanism of action on the toll-like receptor 4 (TLR4)/ $\mathrm{NF}-\kappa \mathrm{B}$ inflammatory pathway in the course of the disease.

We present the following article in accordance with the ARRIVE reporting checklist (available at https://atm. amegroups.com/article/view/10.21037/atm-22-331/rc).

\section{Methods}

\section{Preparation of TAF}

TAF, a vacuum-dried brownish-yellow powder, was provided by the phytochemical laboratory of the Pharmaceutical Research Institute of Xinjiang Uygur Autonomous Region. Prior to use, $0.5 \%$ sodium carboxymethyl cellulose was used to prepare a $500 \mathrm{mg} / \mathrm{kg}$-bodyweight TAF solution according to the set dose, and 250 and $125 \mathrm{mg} / \mathrm{kg}$-bodyweight TAF solutions were obtained after multiplicative dilution.

\section{Preparation of the poisoning reagent}

The poisoning agent was composed of CS (Snow Lotus), which contained $11 \mathrm{mg}$ of smoke carbon monoxide, $10 \mathrm{mg}$ of tar, $0.9 \mathrm{mg}$ of smoke nicotine, and $10 \mathrm{mg}$ of LPS per stick (Batch No. 713A032, Beijing Solarbio Science \& 
Technology Co., Ltd, China).

\section{Experimental animals}

A total of 46 specific pathogen-free (SPF)-grade male Wistar rats (age, 7-8 weeks; weight, $200 \pm 20$ g) were provided by the Animal Center of Xinjiang Medical University [Production license No. SCXK (Xin) 2018-0002; Combined use license No. SYXK (Xin): 2018-0003].

A protocol was prepared before the study without registration. The use of experimental animals in this study was approved by the Ethics Committee of Xinjiang Medical University (IACUC-20210106-16), in compliance with guidelines of Xinjiang Medical University for the care and use of animals. The animals were placed in a an environment with free access to food, with a temperature $22-24^{\circ} \mathrm{C}$ and humidity of $30-50 \%$.

\section{Grouping and drug administration}

The animals were acclimatised in a SPF environment for 1 week and randomly divided into the following six groups: blank control group $(n=6)$, model control group $(n=8)$, lowdose TAF + model group $(n=8)$, middle-dose TAF + model group ( $\mathrm{n}=8)$, high-dose TAF + model group $(\mathrm{n}=8)$, and positive control + model group $(\mathrm{n}=8)$. The low-, middle-, and high-dose groups were administered 125, 250, and $500 \mathrm{mg} / \mathrm{kg}$ of TAF, respectively, by gavage once a day for 45 days. The positive control + model group received $1 \mathrm{mg} / \mathrm{kg}$ of dexamethasone by gavage once a day for 5 days.

\section{Establishment of the COPD model}

The rats were exposed to CS in a poisoning chamber (21), and all groups, except the blank control group, were exposed to passive smoking once in the morning and once in the afternoon with an interval of $\geq 5 \mathrm{~h}$. The rats were monitored, and observations were recorded daily during the experimental period, including weight, food intake, defecation, activity, and other status data. Each modelling group was not poisoned on day 1 and day 15 . The rats were anaesthetised by intraperitoneal injection of $4 \%$ sodium pentobarbital ( $2 \mathrm{~mL} / \mathrm{kg})$. Subsequently, $0.2 \mathrm{~mL}$ of $1-\mathrm{mg} / \mathrm{mL}$ LPS solution was administered as a non-invasive tracheal drip, and the rats were returned to the original rat cages once they were awake. The success criteria for the establishment of the COPD model were determined based on the imaging of lung tissues, lung function changes, and morphological changes in lung histopathology $(22,23)$.

\section{Sampling and related tests}

\section{General physical observation}

Regarding body mass, the rats were weighed every 3 days during the experiment, and their fur, food intake, mental status, cough, and respiratory secretions were observed daily.

\section{Pulmonary function testing}

Non-invasive pulmonary function tests were performed in rats using the whole-body volume tracing method (24). General, lung volume, conductivity, airway obstruction, and ventilation indices were evaluated in each rat for $5 \mathrm{~min}$ after calming down, and the average values were considered the variable values. The evaluation was as follows: (I) general indices included the inspiratory time ( $\mathrm{Ti}$, time from the beginning of inspiration to the end of inspiration) and expiratory time (Te, time from the beginning of expiration to the end of expiration); (II) lung volume indicators included tidal volume ( $\mathrm{TVb}$, the amount of gas inhaled or exhaled during each breath); (III) conductivity indicators were the maximum inspiratory flow rate (PIF, peak flow rate during inspiration) and maximum expiratory flow rate (PEF, peak flow rate during expiration); (IV) apnoea indicators included PAU (time comparison between early and late expiration) and airway narrowing index (Penh, reflecting airway resistance); (V) the ventilation indicator was the respiratory rate (f, number of breaths per minute).

\section{Lung tissue imaging}

The rats were anesthetised using $4 \%$ pentobarbital $(2 \mathrm{~mL} / \mathrm{kg})$ administered intraperitoneally, placed on a fixed plate and fixed in a supine anterior-posterior position with the chest in a fluoroscopic state under photographic conditions. On the day following all experiments, the rats were imaged using an X-ray machine (Kodak DR3000 Digital radiographic imaging system, Xinjiang Tianhe medical equipment company) under the following settings: voltage, $48 \mathrm{kV}$; current, $100 \mathrm{~mA}$; and current-time product, 5,500 mAs. The results were obtained by two or more attending physicians from the imaging centre of the First Affiliated Hospital of Xinjiang Medical University after reviewing the films $(25,26)$. 
Table 1 Lung histopathology scoring criteria

\begin{tabular}{|c|c|c|}
\hline Content & Microscopic manifestations & Score \\
\hline \multirow{3}{*}{$\begin{array}{l}\text { Degree of } \\
\text { inflammation in } \\
\text { the lung tissue }\end{array}$} & Mild cellular infiltration (scattered inflammation with occasional partial aggregation) & 1 \\
\hline & Moderate cellular infiltration (inflammatory clusters that have not yet reached the submucosa of the bronchi) & 2 \\
\hline & Severe cellular infiltration (massive inflammatory clusters, invading the submucosa of the bronchi) & 3 \\
\hline \multirow{3}{*}{$\begin{array}{l}\text { Degree of } \\
\text { emphysema }\end{array}$} & Small amount of alveolar emphysema visible under the dirty pleural layer of the lung tissue & 1 \\
\hline & Between 1 and 3 points & 2 \\
\hline & Emphysematous lesions occupy more than $2 / 3$ of the entire section & 3 \\
\hline \multirow{2}{*}{$\begin{array}{l}\text { Degree of mucus } \\
\text { secretion }\end{array}$} & No mucus in the lumen & 0 \\
\hline & Partially filled the lumen & 3 \\
\hline
\end{tabular}

\section{Routine blood tests}

White blood cell (WBC), neutrophil (N), lymphocyte (LYM), monocyte (MON), eosinophil (EOS), and basophil (BAS) counts were measured using a fully automated blood cell analyser.

\section{Wet-to-dry weight ratio of the lung parenchyma}

After the right lung lobe was weighed, it was dried and weighed again. The median wet-to-dry weight ratio (W/D) was calculated as wet weight/dry weight $\times 100 \%$.

\section{Histopathological observation of the lungs}

Tissues of the right lung lobe were cut into paraffin sections and subjected to haematoxylin and eosin (HE) staining. The morphological and structural changes of lung tissues were observed under a light microscope. The lung tissue sample was then divided into four grades for scoring according to the degree of inflammation, emphysema, and mucus secretion. The scoring criteria for lung histopathology are presented in Table 1.

\section{Measurement of alveolar lavage fluid inflammatory factors}

The levels of cytokines (IL-1, IL-6, IL-10, and TNF- $\alpha$ ) in the supernatant of bronchoalveolar lavage fluid (BALF) in each rat group were measured by enzyme-linked immunosorbent assay (ELISA), and the specific procedural requirements were performed according to the kit's instructions.

\section{Measurement of the protein contents of TLR4, IKKa, p65, and IL-1及}

In each rat group, the frozen middle lobe of the right lung was removed, the tissue was cut, and approximately $100 \mathrm{mg}$ of the tissue was taken from each group. Moreover, the relative protein contents of TLR4, IKKa, p65, and IL$1 \beta$ were measured by western blot.

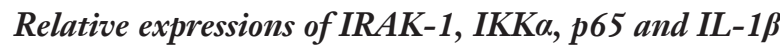 $m R N A$}

The relative expressions of IRAK-1, IKK $\alpha$, p65, and IL-1 $\beta$ mRNA were detected by RT-PCR (Table 2).

\section{Statistical analysis}

All statistical analyses were performed using GraphPad Prism 7 (GraphPad Software Inc., La Jolla, CA, USA) to compare gene expression, viability, and methylation changes between the treatment groups. The IBM SPSS, version 21.0, (IBM Corp., Armonk, NY, USA) statistical software was used for data analysis, and measurement data were expressed as mean \pm standard deviation. Normally 
distributed data were analyzed by one-way analysis of variance, and skewed and rank data were analysed by the rank-sum test with test level $\alpha=0.05$. $\mathrm{P}<0.05$ was considered to indicate a statistically significant difference (27).

\section{Results}

\section{Respiratory secretion and mental status}

Compared with the blank control group, the secretion in the model group increased significantly $(\mathrm{P}<0.01)$, and the treatment effect was more significant in the positive

Table 2 Primer sequences of each gene

\begin{tabular}{|c|c|}
\hline Gene & Primer sequence \\
\hline \multirow[t]{2}{*}{$\beta$-actin } & F-CCCATCTATGAGGGTTACGC \\
\hline & R-TTTAATGTCACGCACGATTTC \\
\hline \multirow[t]{2}{*}{ IRAK-1 } & F-GCACCCACAACTTCTCGGAG \\
\hline & R-CACCGTGTTCCTCATCACCG \\
\hline \multirow[t]{2}{*}{$I K K \alpha$} & F-ATGGCGAGACGTTAGCACAA \\
\hline & R-TCCGCAGGAAAGATGACCAC \\
\hline \multirow[t]{2}{*}{$p 65$} & F-GGTGTGTGAGGACTATGCCA \\
\hline & R-TAGGGTGCAGGCAACGAAG \\
\hline \multirow[t]{2}{*}{$I L-1 \beta$} & F-ATGATGGCTTATTACAGTGGCAA \\
\hline & R-GTCGGAGATTCGTAGCTGGA \\
\hline
\end{tabular}

control group $(\mathrm{P}<0.05)$. Respiratory secretions decreased with increasing concentration in each TAF group, with the most marked decrease in the middle- and high-dose groups, suggesting that TAF can significantly promote the production of respiratory secretions during COPD development in normal rats $(\mathrm{P}=0.000)$.

During COPD development in normal rats, the animals in the model group showed significant mental abnormalities, such as agitation and daily mental depression during gavage and staining. However, the mental status of the TAF group was improved with increasing drug concentration, and the therapeutic effect of dexamethasone did not significantly improve the mental status (Table 3).

\section{Lung function}

Compared with the blank control group, $\mathrm{f}$, Penh, and PAU were significantly greater $(\mathrm{P}<0.01)$, while $\mathrm{TVb}, \mathrm{Ti}, \mathrm{Te}, \mathrm{PIF}$, and $\mathrm{PEF}$ were significantly reduced $(\mathrm{P}<0.01)$ in the model group. This finding suggests that COPD increases the respiratory rate, and promotes airway narrowing and apnoea.

Compared with the model group, TVb, Ti, Te, PIF, and PEF were significantly increased, while $\mathrm{f}$, Penh, and PAU were significantly decreased in the positive control group $(\mathrm{P}<0.01)$. This finding suggests that dexamethasone can effectively improve the respiratory function of COPD rats within a short period of time. The downregulation of $f$, Penh, and PAU in each TAF group was significantly decreased, the downregulation of $\mathrm{f}$ increased with increasing

Table 3 Changes in respiratory secretions and mental status of each group (mean \pm SEM)

\begin{tabular}{|c|c|c|c|c|c|c|c|c|c|}
\hline Group & \multicolumn{4}{|c|}{ Respiratory secretions } & Rank mean & \multicolumn{3}{|c|}{ Mental state } & Rank mear \\
\hline Blank control group $(n=6)$ & 6 & 0 & 0 & 0 & 5.00 & 6 & 0 & 0 & 6.50 \\
\hline Model group $(n=8)$ & 0 & 0 & 2 & 6 & $39.88^{\Delta \Delta}$ & 0 & 1 & 7 & $38.88^{\Delta \Delta}$ \\
\hline Positive control group $(n=8)$ & 0 & 5 & 3 & 0 & $22.94^{\Delta * \star}$ & 1 & 4 & 3 & $28.19^{\Delta \Delta}$ \\
\hline Middle-dose TAF group $(n=8)$ & 0 & 5 & 3 & 0 & $22.94^{\Delta \star \star}$ & 2 & 5 & 1 & $21.75^{\Delta \star \star}$ \\
\hline High-dose TAF group $(n=8)$ & 3 & 3 & 2 & 0 & $16.44^{\star \star \nabla}$ & 3 & 5 & 0 & $17.44^{\star \star}$ \\
\hline $\mathrm{H}$ & \multicolumn{4}{|c|}{29.233} & \multicolumn{5}{|c|}{27.105} \\
\hline$P$ & \multicolumn{4}{|c|}{0.000} & \multicolumn{5}{|c|}{0.000} \\
\hline
\end{tabular}

${ }^{\Delta}, \mathrm{P}<0.05,{ }^{\Delta}, \mathrm{P}<0.01$, compared with the blank group; ${ }^{\star}, \mathrm{P}<0.05,{ }^{\star \star}, \mathrm{P}<0.01$, compared with the model group; ${ }^{\nabla}, \mathrm{P}<0.05$, compared with the low-dose group. TAF, total flavonoids of Trollius altaicus. 
Table 4 Changes in lung function indicators (mean \pm SEM)

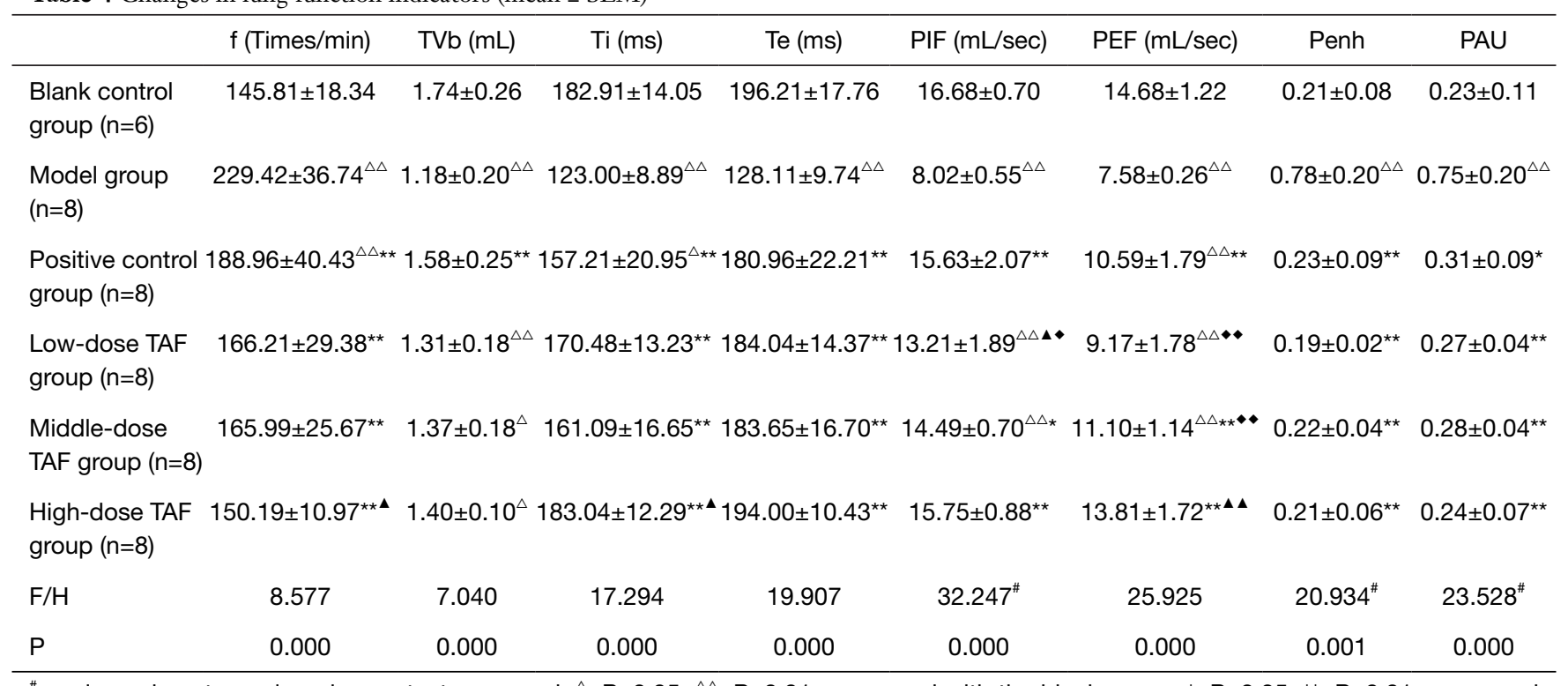

\#, variance is not equal; rank-sum test was used; ${ }^{\Delta}, \mathrm{P}<0.05,{ }^{\Delta \Delta}, \mathrm{P}<0.01$, compared with the blank group; ${ }^{*}, \mathrm{P}<0.05,{ }^{* *}, \mathrm{P}<0.01$, compared with the model group; ${ }^{\mathbf{}}, \mathrm{P}<0.05,{ }^{\mathbf{\Lambda}}, \mathrm{P}<0.01$, compared with the positive control group; ${ }^{\bullet}, \mathrm{P}<0.05$, compared with the high-dose group. TAF, total flavonoids of Trollius altaicus.

TAF concentration, and the downregulation result was better than that of the positive control group. TVb, Ti, Te, PIF, and PEF were significantly upregulated in each TAF group, among which the prolongation effect of $\mathrm{Ti}$ and $\mathrm{Te}$ was better than that of the positive control group, and PIF and PEF demonstrated a significant tendency to increase with the increasing drug concentration $(\mathrm{P}<0.01)$. Also, the PEF increase in the middle- and high-dose groups was higher than that in the positive control group. This finding suggests that TAF, as a preventive drug, can effectively delay the progression of lung function damage during COPD development in rats (Table 4).

\section{Lung imaging examination}

The lung imaging results revealed the following: the rat lungs in the blank control group were clear and bright, and lung tissue texture were normal; the model group had increased lung surface texture, pneumonia, and moderate emphysema in each one, all inflammation assessments were higher than moderate; the positive control group also had moderate emphysema and increased lung surface texture. Compared with the model group and positive control group, the low-dose group had mild emphysema, the middle-dose group had increased lung surface texture and significantly better than the low-dose group; the high-dose group exhibited clear and bright lung fields and significantly better than the middle-dose group. This finding suggests that TAF can effectively alleviate lung parenchymal lesions during COPD development in normal rats (Figure 1).

\section{Complete blood count}

The differences in WBC, LYM, and EOS counts between the groups were significant $(\mathrm{P}=0.000, \mathrm{P}=0.000$, and $\mathrm{P}=0.001$, respectively). There was a trend of $\mathrm{N}$ and $\mathrm{MON}$ count downregulation in each TAF group; however, the difference was not statistically significant when compared with the other groups. The leukocyte, LYM, and EOS counts were significantly higher in the model group than in the blank control group $(\mathrm{P}<0.01, \mathrm{P}<0.01$, and $\mathrm{P}<0.05$, respectively), and the corresponding cell counts in the positive control group were significantly lower than those in the model group $(\mathrm{P}<0.01, \mathrm{P}<0.01$, and $\mathrm{P}<0.05$, respectively). Among the TAF groups, the downregulation of leukocyte, LYM, and EOS counts was most significant in the highdose group $(\mathrm{P}<0.01)$, and the downregulation of the LYM count was also significant in the middle-dose group $(\mathrm{P}<0.05)$. Although the downregulation trend of the $\mathrm{N}$ and $\mathrm{MON}$ counts in each TAF group was not statistically significant, the downregulation effect was elevated with increasing TAF concentrations. 

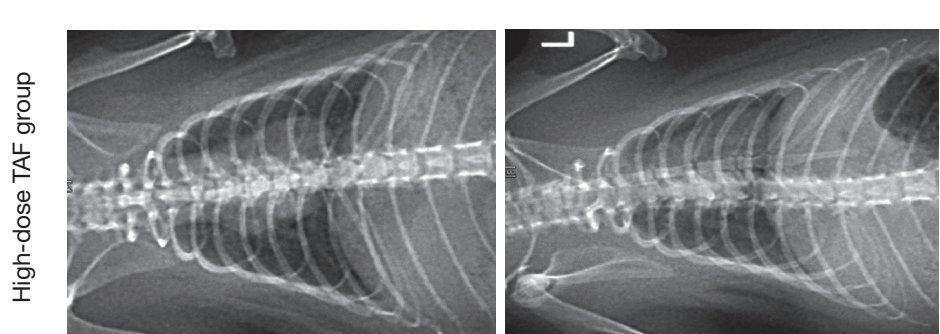

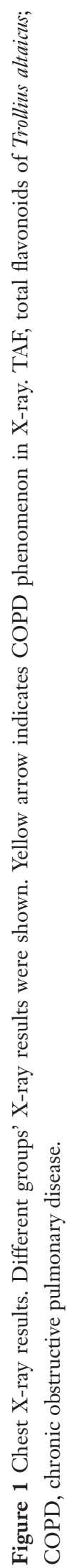
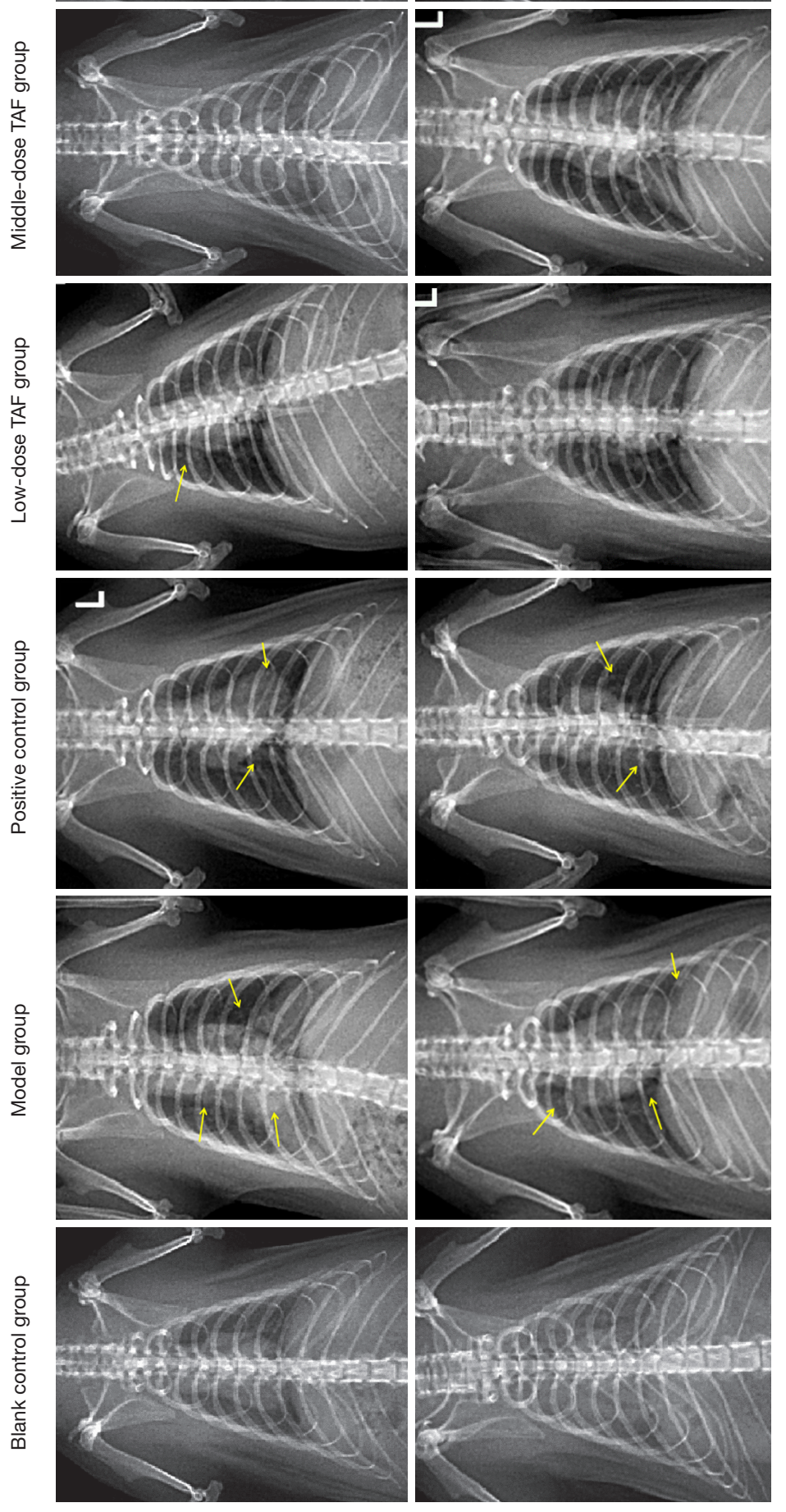
Table 5 Changes in blood cell counts (mean \pm SEM)

\begin{tabular}{|c|c|c|c|c|c|}
\hline & WBC $\left(10^{9} / \mathrm{L}\right)$ & $N\left(10^{9} / L\right)$ & $\operatorname{LYM}\left(10^{9} / \mathrm{L}\right)$ & $\operatorname{MON}\left(10^{9} / \mathrm{L}\right)$ & $\operatorname{EOS}\left(10^{9} / \mathrm{L}\right)$ \\
\hline Model group $(n=8)$ & $10.66 \pm 1.33^{\Delta \Delta}$ & $1.50 \pm 0.48$ & $8.27 \pm 0.91^{\Delta \Delta}$ & $0.66 \pm 0.25$ & $0.15 \pm 0.05^{\Delta}$ \\
\hline Positive control group $(n=8)$ & $5.88 \pm 1.58^{\star \star}$ & $1.72 \pm 1.00$ & $3.54 \pm 0.92^{\star *}$ & $0.51 \pm 0.14$ & $0.07 \pm 0.04^{\star *}$ \\
\hline Low-dose TAF group $(n=8)$ & $8.43 \pm 2.12^{\mathbf{A}}$ & $1.57 \pm 0.39$ & $6.07 \pm 1.70^{\star \Delta \Delta}$ & $0.51 \pm 0.19$ & $0.20 \pm 0.21^{\Delta \Lambda \Delta \bullet}$ \\
\hline High-dose TAF group $(n=8)$ & $6.77 \pm 1.77^{\star \star}$ & $1.15 \pm 0.20$ & $5.08 \pm 1.53^{\star \star}$ & $0.42 \pm 0.14$ & $0.07 \pm 0.03^{\star \star}$ \\
\hline $\mathrm{F} / \mathrm{H}$ & 8.003 & 1.561 & 0.217 & 1.540 & $20.624^{\#}$ \\
\hline $\mathrm{P}$ & 0.000 & 0.193 & 0.000 & 0.199 & 0.001 \\
\hline
\end{tabular}

\#, variance is not equal; rank-sum test was used; ${ }^{\Delta}, \mathrm{P}<0.05,{ }^{\Delta}, \mathrm{P}<0.01$, compared with the blank group; ${ }^{*}, \mathrm{P}<0.05,{ }^{\star \star}, \mathrm{P}<0.01$, compared with the model group; ${ }^{\mathbf{\Delta}}, \mathrm{P}<0.05,{ }^{\mathbf{\Delta}}, \mathrm{P}<0.01$, compared with the positive control group; ${ }^{\bullet}, \mathrm{P}<0.05$, compared with the high-dose group. TAF, total flavonoids of Trollius altaicus.

Table 6 Wet-to-dry weight ratio in each group (mean \pm SEM)

\begin{tabular}{|c|c|}
\hline Group & W/D \\
\hline Blank control group $(n=6)$ & $1.85 \pm 0.22$ \\
\hline Model group $(n=8)$ & $3.84 \pm 0.60^{\triangle \Delta}$ \\
\hline Positive control group $(n=8)$ & $3.60 \pm 0.83^{\Delta \Delta}$ \\
\hline Low-dose TAF group $(n=8)$ & $2.38 \pm 0.36^{\star \star \Delta \Lambda}$ \\
\hline Middle-dose TAF group $(n=8)$ & $1.84 \pm 0.45^{\star \star \Delta \mathbf{\Delta}}$ \\
\hline High-dose TAF group $(n=8)$ & $1.76 \pm 0.34^{\star \star \Delta \Delta}$ \\
\hline $\mathrm{F}$ & 25.679 \\
\hline$P$ & 0.000 \\
\hline \multicolumn{2}{|c|}{$\begin{array}{l}{ }^{\Delta \Delta}, \mathrm{P}<0.01, \text { compared with the blank group; }{ }^{* *}, \mathrm{P}<0.01 \text {, } \\
\text { compared with the model group; }{ }^{\Delta \Delta}, \mathrm{P}<0.01 \text {, compared with the } \\
\text { positive control group. TAF, total flavonoids of Trollius altaicus. } \mathrm{F} \\
\text { means the result of ANOVA of each group; } \mathrm{P} \text { means the } \mathrm{P} \text { value } \\
\text { of ANOVA. }\end{array}$} \\
\hline
\end{tabular}

After COPD development in normal rats, although there was no significant blood routine manifestation of acute exacerbation, the leukocyte, LYM, and EOS counts showed an upregulation trend, and the administration of TAF prevented significant abnormalities of these indicators. Moreover, comparison with the positive control group suggested that the intensity of the effects of TAF on whole blood cells was milder than that of dexamethasone (Table 5).

\section{Pathological changes of lung tissues}

Wet-to-dry weight ratio

The W/D was significantly higher in the model and positive control groups than in the blank control group, and significantly lower in each drug group than in the model and positive control groups. In the drug group, the W/ $\mathrm{D}$ tended to decrease with increasing doses; however, the difference between groups was not statistically significant (Table 6).

\section{Observation of the lung parenchyma}

Based on the appearance, there were no evident changes in the lung parenchyma of the high-dose and blank control groups. The lesions in the model group were the most evident, with a predominance of black spots and individual purulent-like lesions. The positive control group and lowdose group had a few black spots, and the parenchyma of the middle-dose group occasionally showed black spots (Figure 2).

\section{HE staining results}

As for HE staining, no abnormal changes were observed in the lung tissue of the control group. The lung tissue of the model rats showed interstitial focal inflammatory cell infiltration, interstitial fibrous tissue hyperplasia, focal pulmonary haemorrhage, and inflammatory exudates in the bronchial lumen. The lung tissue of the positive control rats displayed small amounts of fibrous tissue hyperplasia and inflammatory cell infiltration, without other pathological changes. The lung tissues of the low-dose group exhibited fibrous tissue hyperplasia and inflammation. The lung tissues of rats in the low-dose group showed fibrous tissue hyperplasia with inflammatory cell infiltration and inflammatory exudate in the bronchial lumen (Figure 3). 

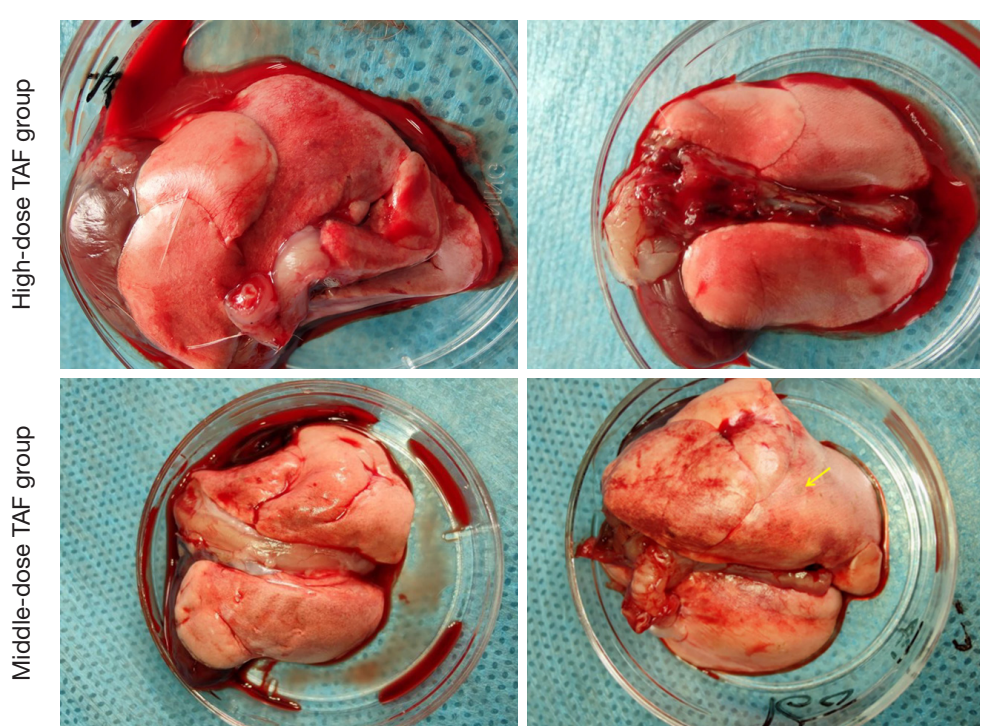

吾
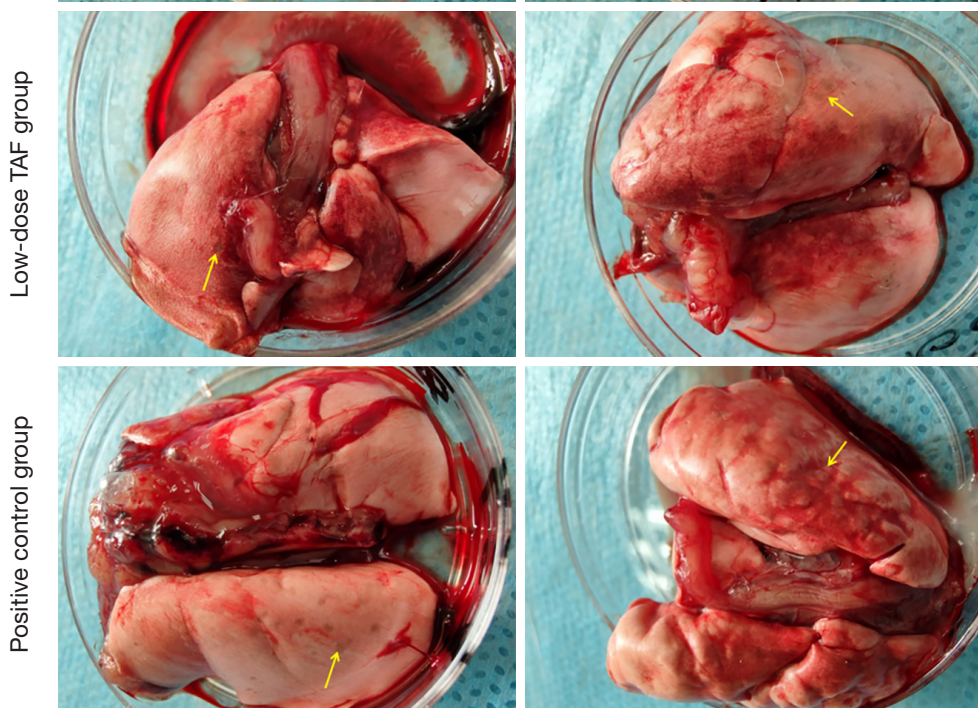

量

节
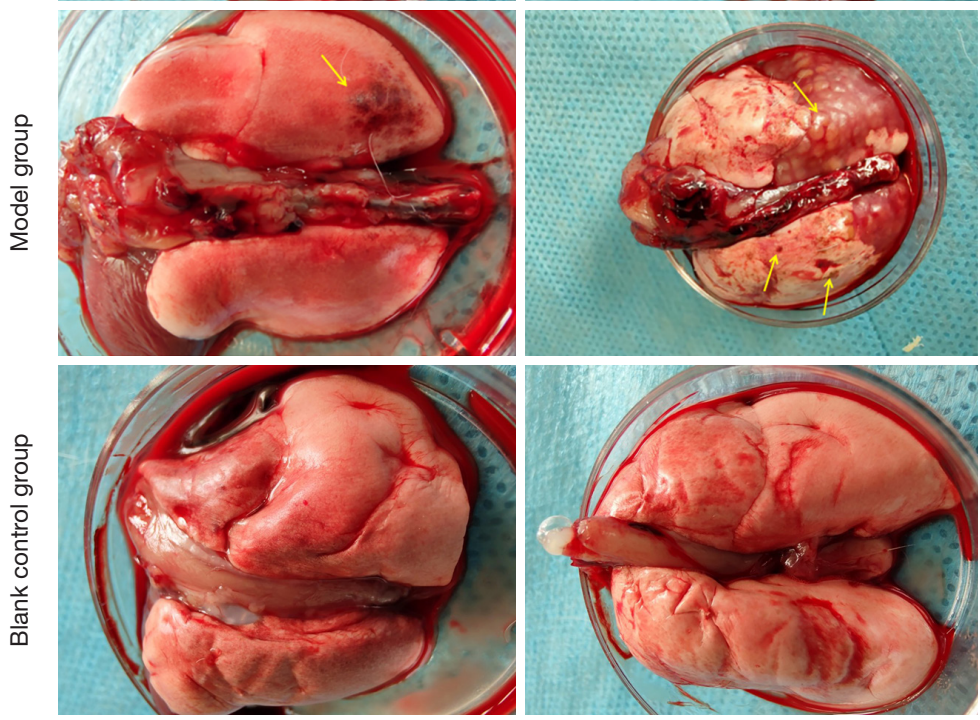

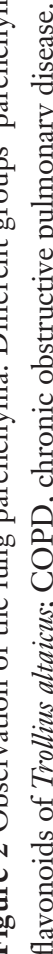



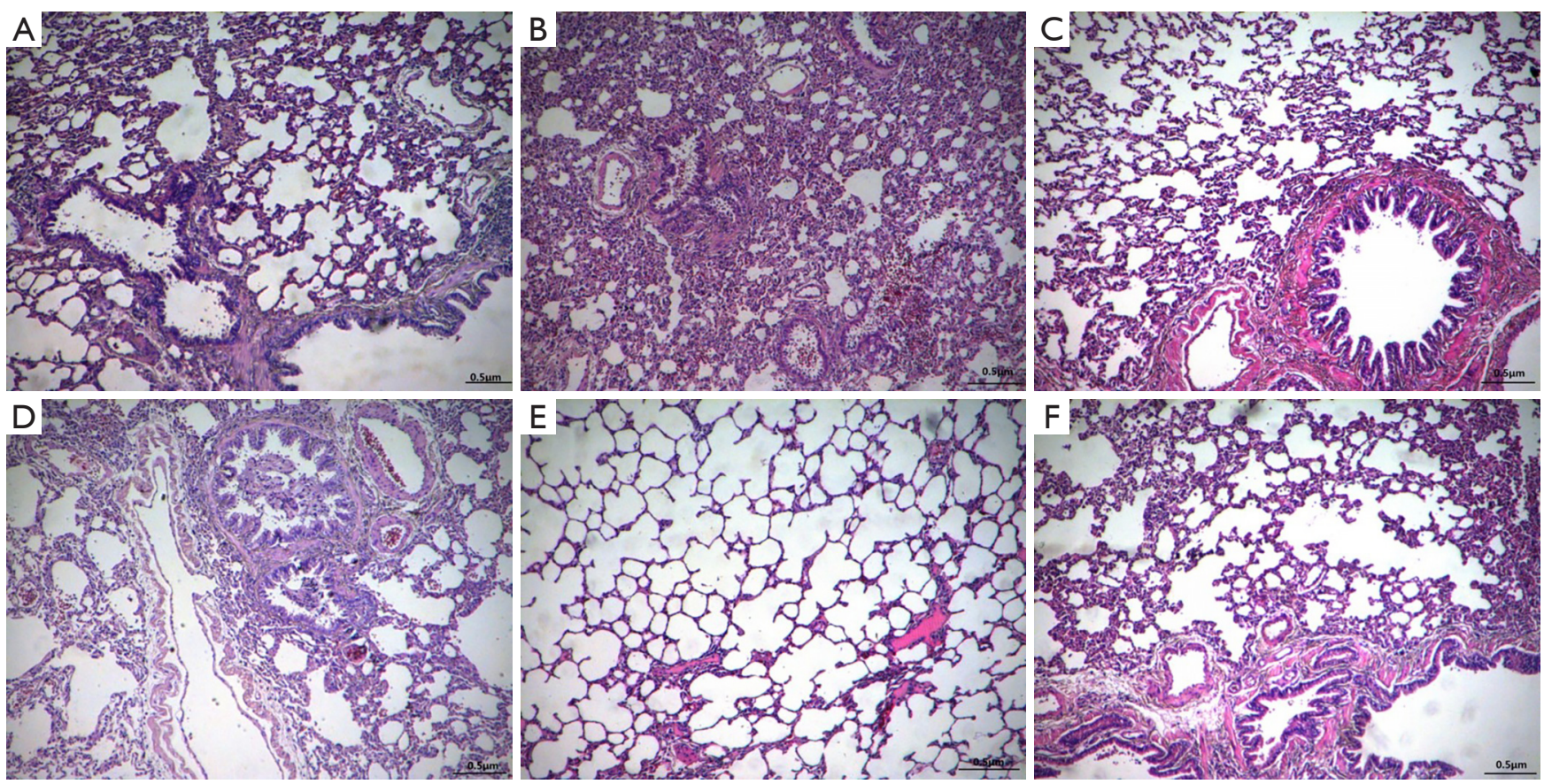

Figure $3 \mathrm{HE}$ staining results $\times 100$. (A) Blank control; (B) model group; (C) positive control group; (D) low-dose TAF group; (E) middledose TAF group; (F) high-dose TAF group. TAF, total flavonoids of Trollius altaicus.

\section{Pathological grading}

When the pathological scores of each group were compared with the model group, the drug intervention was found to significantly improve the degree of inflammation, emphysema, and mucus secretion in lung tissues, and theintervention effect was markedly most noticeable in the middle- and high-dose groups. With increasing drug concentrations, the pathological score showed a decreasing trend, which was consistent with the lung parenchyma findings, suggesting that the increase in drug concentration enhanced its effect of preventing COPD development in rats (Table 7).

\section{Effect of TAF on inflammatory cells in BALF}

The expression levels of IL-1 $\beta$, IL-6, IL-8, IL-10, TNF- $\alpha$, and TGF-1 $\beta$ in BALF were measured using the ELISA kit method, and the overall trend was similar to the serum results. The levels of IL- $1 \beta$, IL- 6 , IL- 8 , TNF- $\alpha$, and TGF- $1 \beta$ were significantly higher in the model group than in the blank control group, and the differences were all statistically significant $(\mathrm{P}<0.001)$. However, IL-10 showed a markedly decrease trend $(\mathrm{P}<0.001)$. Compared with the model group, the effects of the positive control group and each drug group on inflammatory factors were significant. Among them, the downregulation effect of each TAF group on IL-6, IL-8 and TNF- $\alpha$ was notably enhanced with increasing drug concentrations, and its sensitivity was similar to that of the positive control group. The downregulation effect of TAF on IL-1 $\beta$ was enhanced with increasing drug concentrations, and the effect of the highdose group was similar to that of the positive control group. The upregulation effect of TAF on IL-10 was enhanced with increasing drug concentration, and the effect of the highdose group was similar to that of the positive control group. Compared with the serum results, the downregulation effect of TAF on TGF- $\beta 1$ in BALF was significant, although it did not show a changing trend with the concentration gradient. However, the overall downregulation level was better than that of the positive control group (Table 8, Figure 4).

These results indicate that TAF can significantly reduce the protein expressions of IL-1 $\beta$, IL- 6 , IL- 8 , TGF- $\beta 1$, and TNF- $\alpha$ in the alveolar lavage fluid and markedly increase the protein expression of IL-10, thereby regulating the organism and preventing COPD development.

\section{Effects of TAF on TLR4, IKKa, P65, and IL-1及 in lung tissue proteins}

Changes in TLR4, IKK $\alpha, \mathrm{p} 65$, and IL-1 $\beta$ indicators in the 
Table 7 Lung histological grading and scoring (mean \pm SEM)

\begin{tabular}{lccc}
\hline Group & Inflammation & Emphysema & Mucus \\
\hline Blank control group $(n=6)$ & $0.00 \pm 0.00$ & $0.00 \pm 0.00$ & $0.00 \pm 0.00$ \\
Model group $(n=8)$ & $2.20 \pm 0.45^{\Delta \Delta}$ & $2.20 \pm 0.45^{\Delta \Delta}$ & $1.80 \pm 0.45^{\Delta \Delta}$ \\
Positive control group $(n=8)$ & $0.80 \pm 0.84^{\star}$ & $0.80 \pm 0.84^{\star \star}$ & $0.20 \pm 0.45^{\star \star}$ \\
Low-dose TAF group $(n=8)$ & $1.60 \pm 0.55^{\Delta \Delta}$ & $1.20 \pm 0.45^{\Delta}$ & $1.00 \pm 0.00^{\Delta \Delta}$ \\
Middle-dose TAF group $(n=8)$ & $1.20 \pm 0.84^{\Delta}$ & $1.00 \pm 0.71^{\star}$ & $0.60 \pm 0.55$ \\
High-dose TAF group $(n=8)$ & $0.40 \pm 0.55^{\star}$ & $0.40 \pm 0.55^{\star \star}$ & $0.40 \pm 0.55^{\star}$ \\
F/H & $18.786^{\#}$ & 9.011 & $19.829^{\#}$ \\
$P$ & 0.002 & 0.000 & 0.001 \\
\hline
\end{tabular}

\#, variance is not equal; rank-sum test was used. ${ }^{\Delta}, \mathrm{P}<0.05,{ }^{\Delta}, \mathrm{P}<0.01$, compared with the blank group; ${ }^{*}, \mathrm{P}<0.05,{ }^{\star *}, \mathrm{P}<0.01$, compared with the model group; $" \mathrm{P}<0.05$, compared with the high-dose group. TAF, total flavonoids of Trollius altaicus.

Table 8 Changes in BALF levels of inflammatory cells (mean \pm SEM)

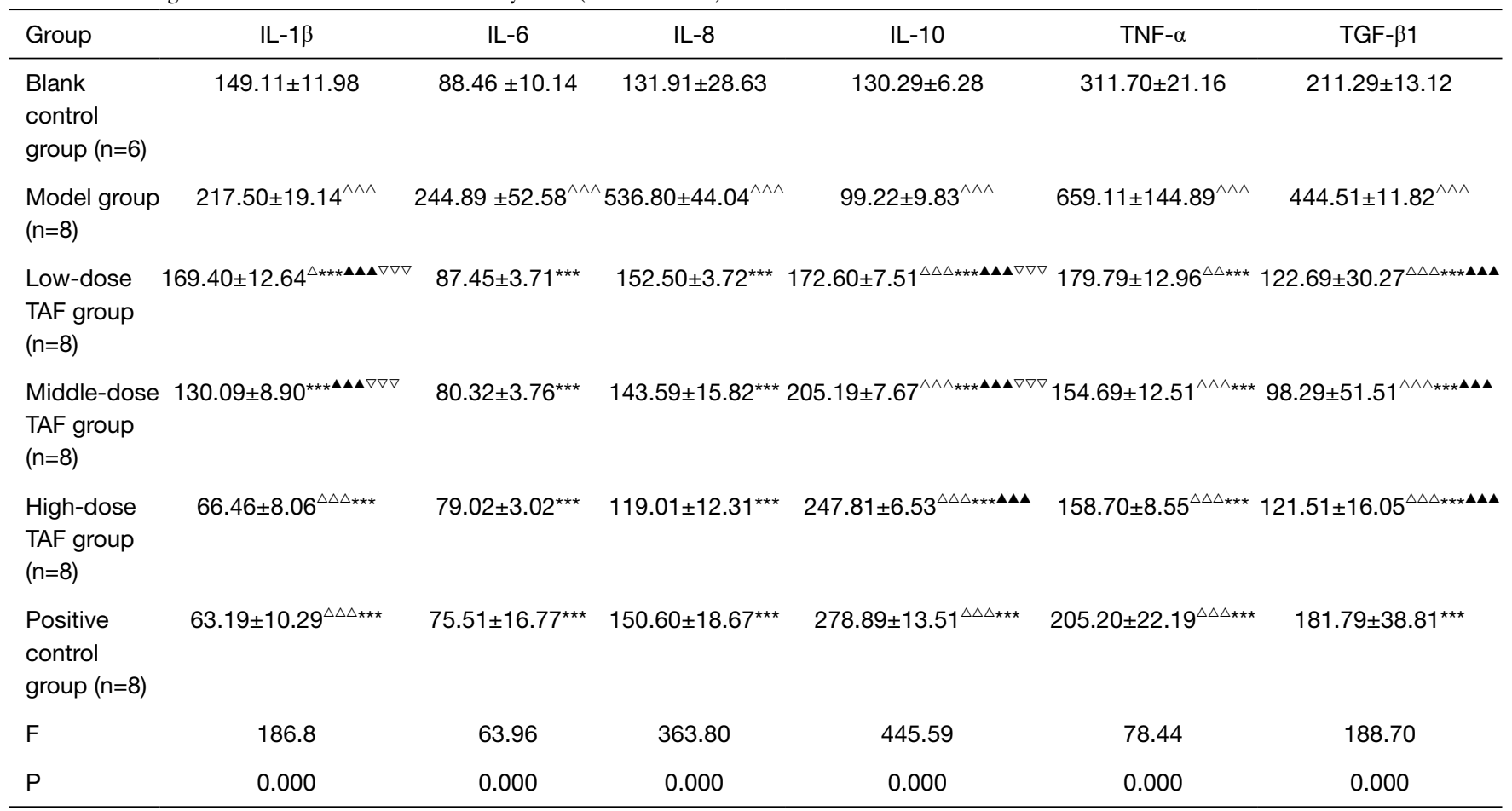

${ }^{\Delta}, \mathrm{P}<0.05,{ }^{\Delta \Delta}, \mathrm{P}<0.01,{ }^{\Delta \Delta \Delta}, \mathrm{P}<0.001$, compared with the blank group; ${ }^{* \star *}, \mathrm{P}<0.001$, compared with the model group; ${ }^{\Delta \Delta \Delta}, \mathrm{P}<0.001$, compared with the positive control group; ${ }^{\nabla \nabla}, \mathrm{P}<0.001$, compared with the high-dose group. BALF, bronchoalveolar lavage fluid; TAF, total flavonoids of Trollius altaicus.

lung tissues of each rat group were detected by western blot. The expression of each index was low in the blank control group, and the protein expressions of TLR4, IKK $\alpha, \mathrm{p} 65$, and IL- $1 \beta$ were significantly increased in the model group. The protein expression of each index tended to decrease with increasing concentration in each TAF group, with the greatest sensitivity of IKK $\alpha$, and the protein inhibition intensity in the high-dose group was similar to that of the positive control group (Table 9 and Figures 5,6). 
IL-1 $\beta$

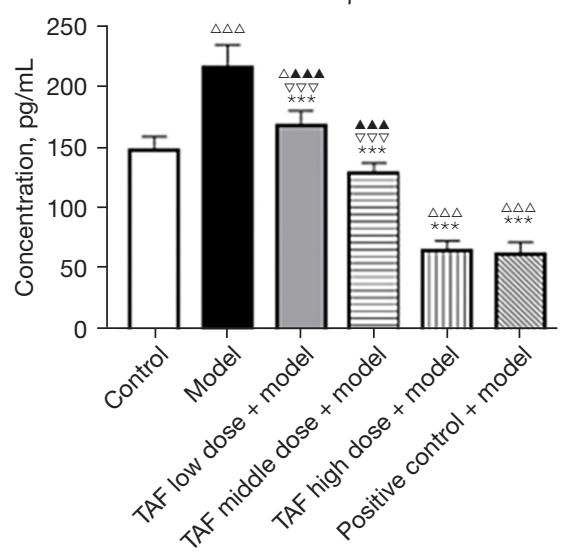

IL-10

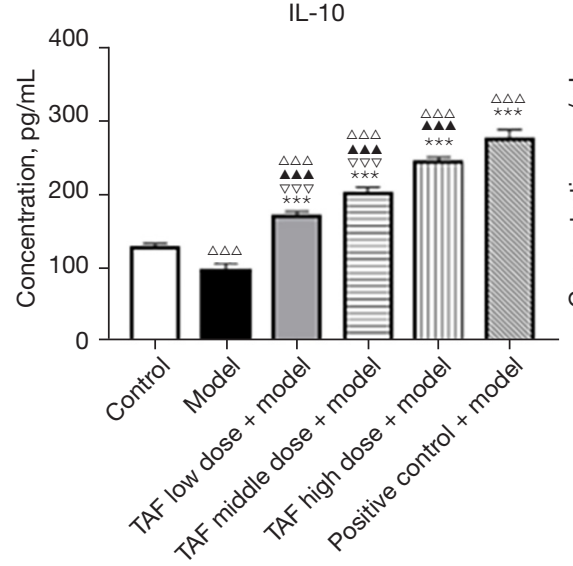

IL-6

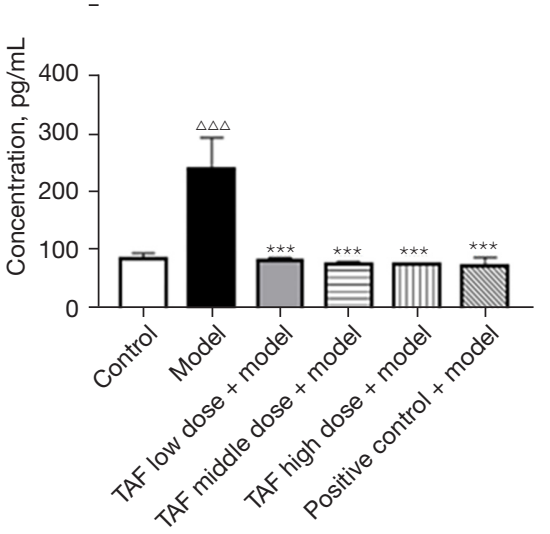

TNF- $\alpha$

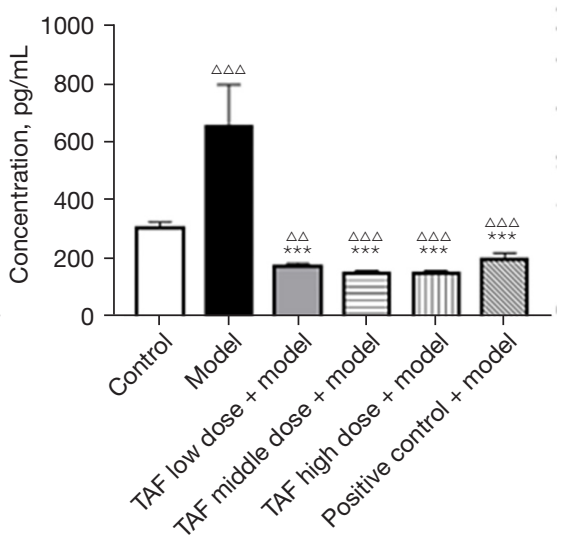

IL-8

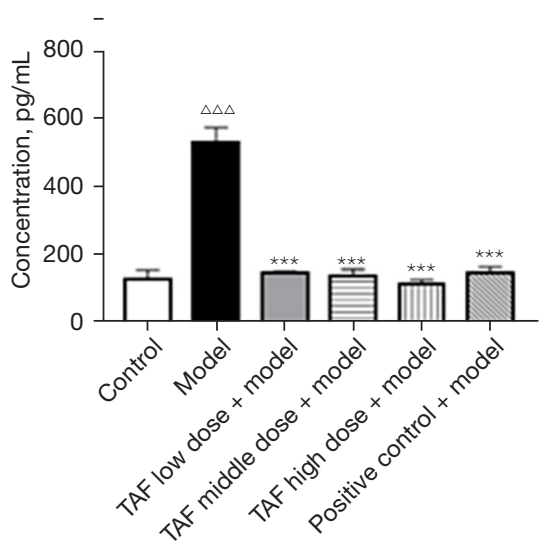

TGF- $\beta 1$

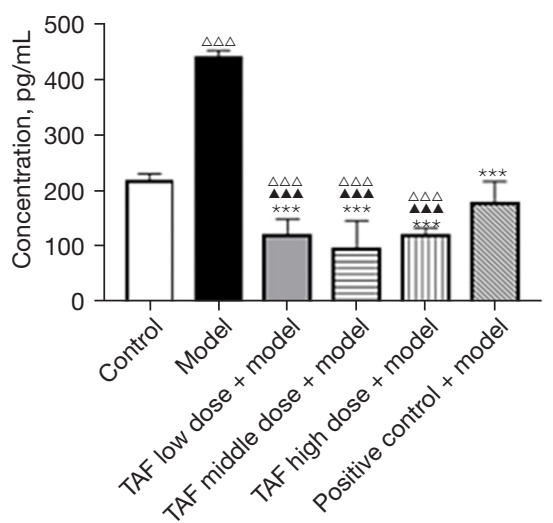

Figure 4 Expression levels of inflammatory cells in each BALF group. ${ }^{\Delta}, \mathrm{P}<0.05, \stackrel{\Delta}{\Delta}, \mathrm{P}<0.01, \stackrel{\Delta \Delta \Delta}{ }, \mathrm{P}<0.001$, compared with the blank group; ***, $\mathrm{P}<0.001$, compared with the model group; ${ }^{\mathbf{\Lambda \Lambda}}, \mathrm{P}<0.001$, compared with the positive control group; ${ }^{\nabla \nabla}, \mathrm{P}<0.001$, compared with the high-dose group. BALF, bronchoalveolar lavage fluid; TAF, total flavonoids of Trollius altaicus.

Table 9 Gray values of TLR4, IKK $\alpha$, p65, and IL-1 $\beta$ protein bands in lung tissues of each group (mean \pm SEM)

\begin{tabular}{|c|c|c|c|c|}
\hline Group & TLR4 & $\mathrm{IKK} \alpha$ & p65 & IL-1 $\beta$ \\
\hline Blank control group $(n=6)$ & $1.75 \pm 0.19$ & $2.36 \pm 0.32$ & $1.40 \pm 0.33$ & $1.05 \pm 0.22$ \\
\hline Model group $(n=8)$ & $3.14 \pm 0.29^{\Delta \Delta \Delta}$ & $3.72 \pm 0.04^{\Delta \Delta \Delta}$ & $2.53 \pm 0.16^{\Delta \Delta \Delta}$ & $2.60 \pm 0.44^{\Delta \Delta}$ \\
\hline Low-dose TAF group $(n=8)$ & $2.91 \pm 0.14^{\triangle \triangle \Delta \Delta \Delta \nabla \nabla}$ & $3.27 \pm 0.18^{\triangle \triangle \Delta \Delta \Delta \nabla \nabla \nabla}$ & $2.24 \pm 0.09^{\triangle \triangle \Delta \Delta \nabla}$ & $2.31 \pm 0.20^{\Delta \Delta \mathbf{\Delta \Delta} \nabla \nabla}$ \\
\hline Middle-dose TAF group $(n=8)$ & $2.57 \pm 0.38^{\Delta \mathbf{\Lambda \Delta} \nabla}$ & $3.01 \pm 0.04^{\triangle * \star \Delta \Delta \mathbf{\Delta} \nabla \nabla}$ & $2.04 \pm 0.19^{\triangle \boldsymbol{\Lambda}}$ & $2.04 \pm 0.29^{\triangle \mathbf{\Delta} \nabla}$ \\
\hline Positive control group $(n=8)$ & $1.62 \pm 0.31^{\star \star \star}$ & $1.89 \pm 0.27^{\star \star \star}$ & $1.28 \pm 0.23^{\star \star \star}$ & $1.01 \pm 0.49^{\star *}$ \\
\hline $\mathrm{F}$ & 18.91 & 36.59 & 15.01 & 12.52 \\
\hline$P$ & 0.000 & 0.000 & 0.000 & 0.000 \\
\hline
\end{tabular}

${ }^{\Delta}, \mathrm{P}<0.05,{ }^{\Delta \Delta}, \mathrm{P}<0.01,{ }^{\Delta \Delta \Delta}, \mathrm{P}<0.001$, compared with the blank group; ${ }^{* \star}, \mathrm{P}<0.01,{ }^{\star \star \star}, \mathrm{P}<0.001$, compared with the model group; ${ }^{\Delta}, \mathrm{P}<0.05$, ${ }^{\mathbf{\Delta}}, \mathrm{P}<0.01,{ }^{\mathbf{\Delta \Delta}}, \mathrm{P}<0.001$, compared with the positive control group; ${ }^{\nabla}, \mathrm{P}<0.05,{ }^{\nabla \nabla}, \mathrm{P}<0.01,{ }^{\nabla \nabla \nabla}, \mathrm{P}<0.001$, compared with the high-dose group. TAF, total flavonoids of Trollius altaicus. 

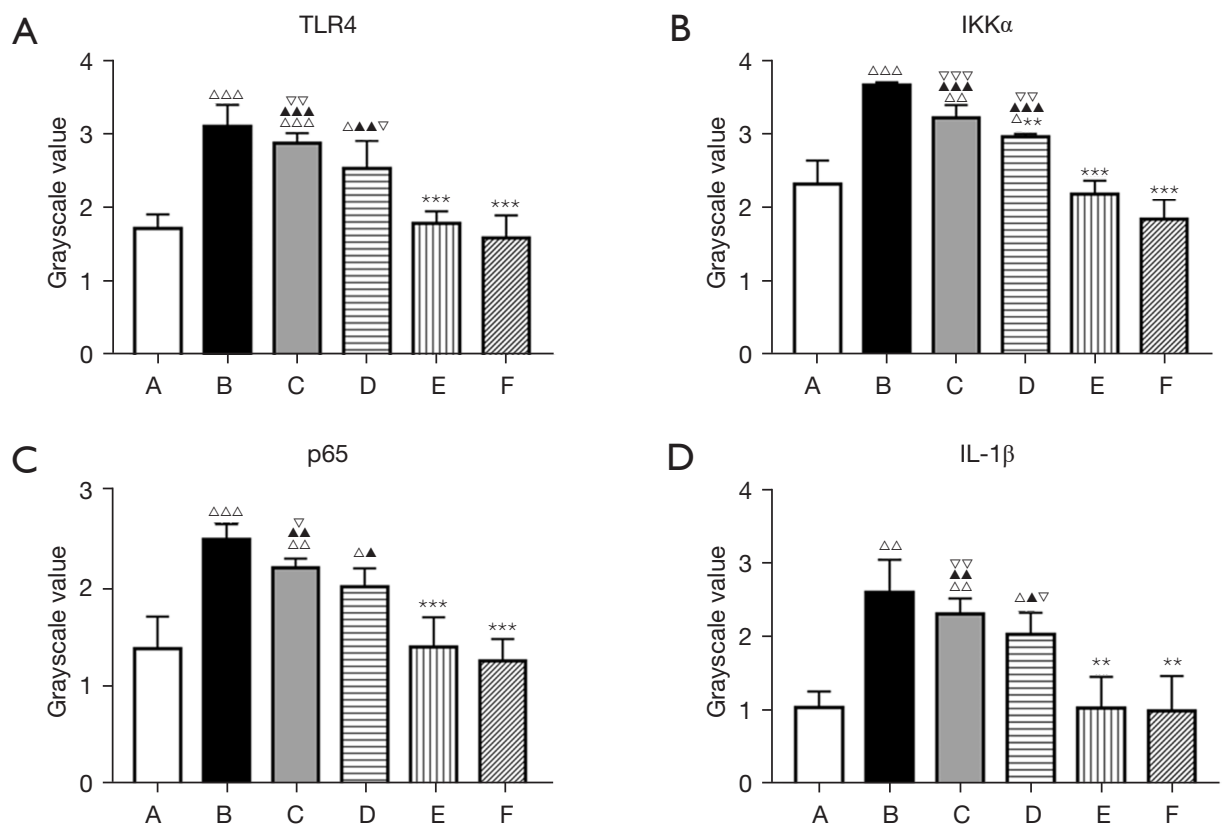

Figure 5 Gray values of TLR4, IKK $\alpha$, p65, and IL-1 $\beta$ protein bands in lung tissues. A: Blank control; B: Model group; C: Positive control group; D: Low-dose TAF group; E: Middle-dose TAF group; F: High-dose TAF group. ${ }^{\Delta}, \mathrm{P}<0.05,{ }^{\Delta}{ }^{,} \mathrm{P}<0.01,{ }^{\Delta \Delta \Delta}, \mathrm{P}<0.001$, compared with the blank group; ; ${ }^{* *}, \mathrm{P}<0.01$, ${ }^{* * *}, \mathrm{P}<0.001$, compared with the model group; ${ }^{\mathbf{\Delta}}, \mathrm{P}<0.05,{ }^{\mathbf{\Delta}}, \mathrm{P}<0.01,{ }^{\mathbf{\Delta} \Delta}$, $\mathrm{P}<0.001$, compared with the positive control group; ${ }^{\nabla}, \mathrm{P}<0.05,{ }^{\nabla \nabla}, \mathrm{P}<0.01,{ }^{\nabla \nabla}, \mathrm{P}<0.001$, compared with the high-dose group. TAF, total flavonoids of Trollius altaicus.

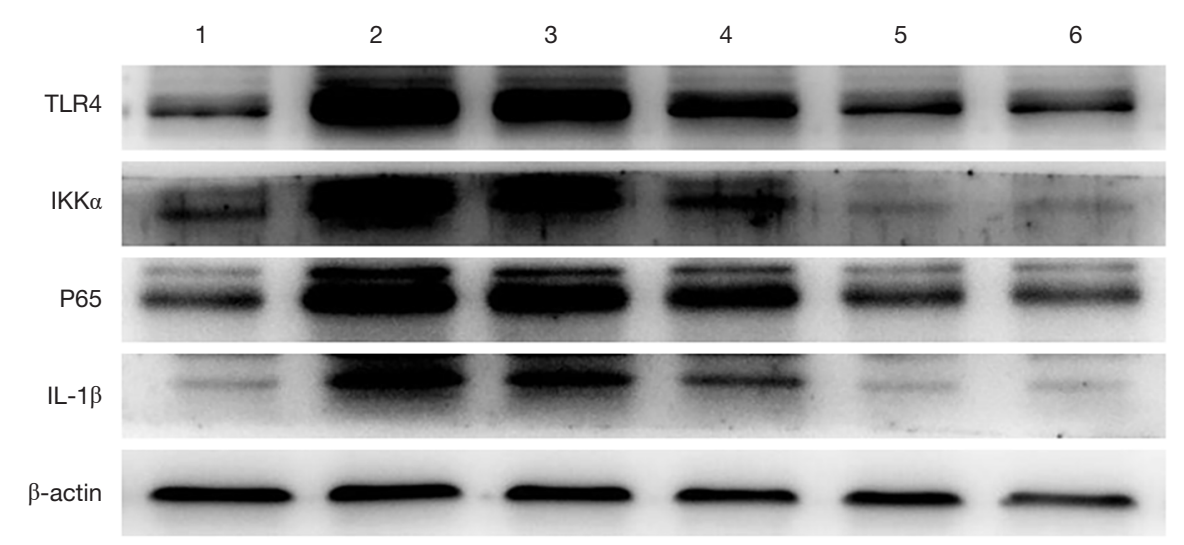

Figure 6 Protein of TLR4, IKK $\alpha$, p65, and IL-1 $\beta$ expression in lung tissues. 1, blank control; 2, model group; 3, low-dose TAF group; 4, middle-dose TAF group; 5, high-dose TAF group; 6, positive control group. TAF, total flavonoids of Trollius altaicus. 

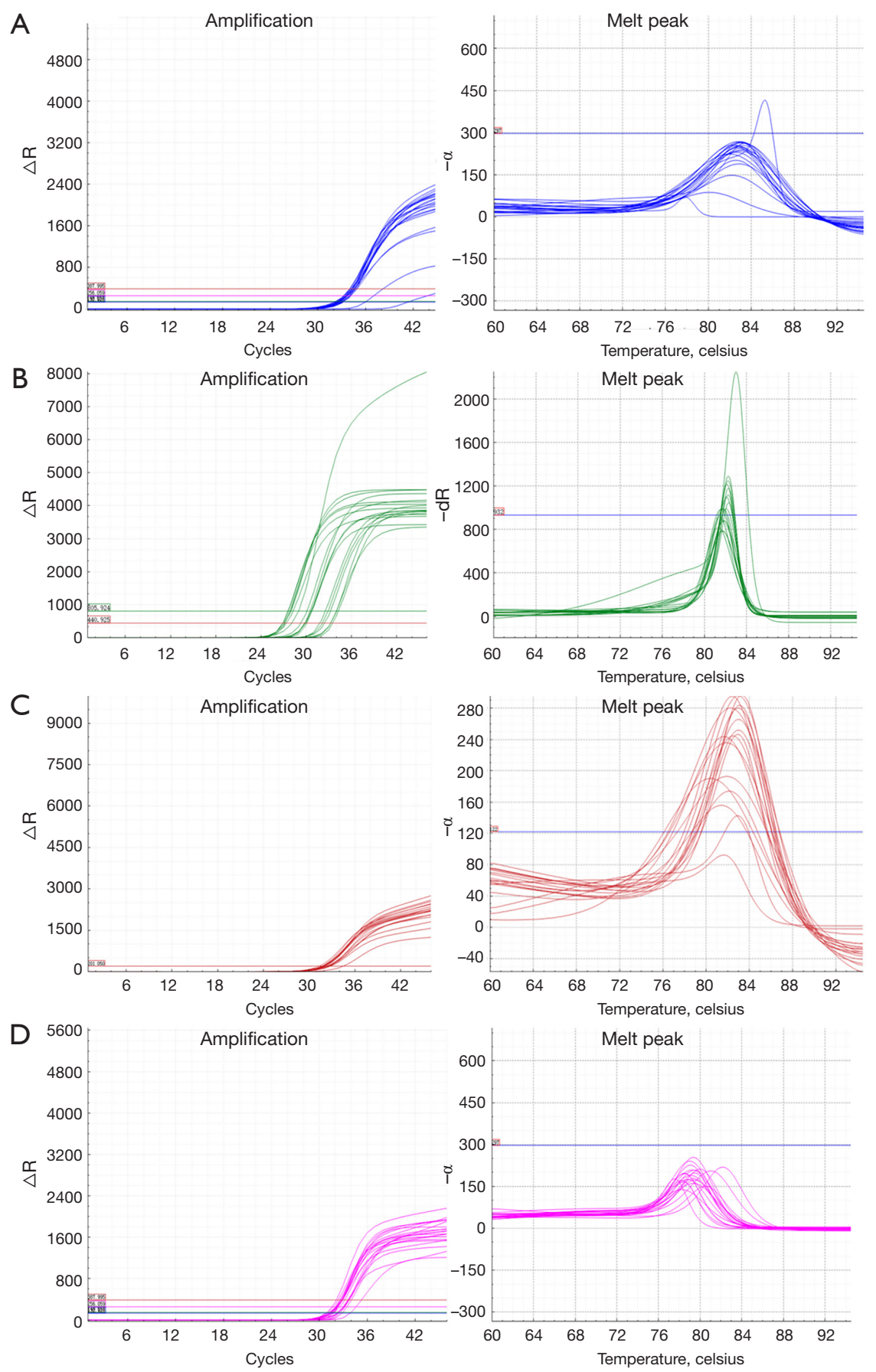

Figure 7 Amplification and dissolution curves of IRAK-1, IKK $\alpha$, p65, and IL-1 $\beta$ genes. (A) IRAK-1; (B) IKK $\alpha$; (C) p65; (D) IL-1 $\beta$.

Effects of TAF on the mRNA expression levels of IRAK-1, IKKa, p65, and IL-1ß in lung tissue proteins

Figure 7 shows the IRAK-1, IKK $\alpha$, p65, and IL-1 beta gene amplification curve and melting curves were unimodal at a reasonable temperature range $\left(80-86^{\circ} \mathrm{C}\right)$. The sample amplification process was good, and there was no nonspecific amplification.

The qRT-PCR results showed that the expressions of IRAK-1, IKK $\alpha$, p65, and IL-1 $\beta$ mRNA were significantly increased in the model group, with statistically significant 
Table 10 mRNA expression levels of IRAK-1, IKK $\alpha$, p65, and IL-1 $\beta$ in lung tissue proteins (mean \pm SEM)

\begin{tabular}{|c|c|c|c|c|}
\hline Group & IRAK-1 & $\mathrm{IKK} \alpha$ & p65 & $\mathrm{IL}-1 \beta$ \\
\hline Model group $(n=8)$ & $4.09 \pm 0.69^{\Delta \Delta \Delta}$ & $0.52 \pm 0.12^{\Delta \Delta \Delta}$ & $1.85 \pm 0.30^{\Delta \Delta \Delta}$ & $5.63 \pm 0.67^{\Delta \Delta \Delta}$ \\
\hline Low-dose TAF group $(n=8)$ & $3.16 \pm 0.19^{\Delta \Delta \Delta_{\star} \Delta \Delta \Delta \nabla \nabla \nabla}$ & $0.28 \pm 0.07^{\star *}$ & $1.29 \pm 0.20^{\Delta \Delta \Delta_{\star} \Delta \Delta \mathbf{\Delta} \nabla \nabla \nabla}$ & $3.24 \pm 0.18^{\Delta \Delta \Delta_{* \star \star \star} \Delta \Delta \Delta \nabla \nabla \nabla}$ \\
\hline Middle-dose TAF group $(n=8)$ & $0.75 \pm 0.16^{\star \star \star}$ & $0.18 \pm 0.02^{\star \star \star \Delta}$ & $0.39 \pm 0.05^{\star \star \star}$ & $0.73 \pm 0.11^{\star \star \star}$ \\
\hline Positive control group $(n=8)$ & $0.41 \pm 0.02^{\Delta * \star \star}$ & $0.39 \pm 0.03^{\Delta \Delta}$ & $0.43 \pm 0.04^{\star \star \star}$ & $0.47 \pm 0.07^{\Delta_{\star \star \star \star}}$ \\
\hline $\mathrm{F}$ & 76.23 & 19.75 & 45.49 & 149.80 \\
\hline$P$ & 0.000 & 0.000 & 0.000 & 0.000 \\
\hline
\end{tabular}

${ }^{\Delta}, \mathrm{P}<0.05,{ }^{\Delta \Delta}, \mathrm{P}<0.01,{ }^{\Delta \Delta \Delta}, \mathrm{P}<0.001$, compared with the blank group; ${ }^{*}, \mathrm{P}<0.05,{ }^{\star \star}, \mathrm{P}<0.01,{ }^{\star \star \star}, \mathrm{P}<0.001$, compared with the model group; ${ }^{\wedge}$, $\mathrm{P}<0.05,{ }^{\Delta \Delta}, \mathrm{P}<0.01,{ }^{\Delta \Delta}, \mathrm{P}<0.001$, compared with the positive control group; ${ }^{\nabla \nabla \nabla}, \mathrm{P}<0.001$, compared with the high-dose group. TAF, total flavonoids of Trollius altaicus.

A
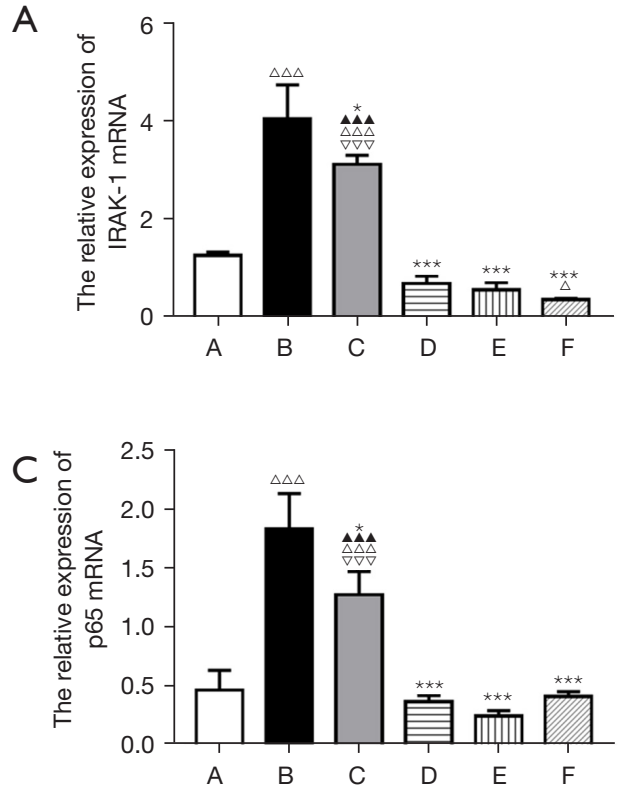

B
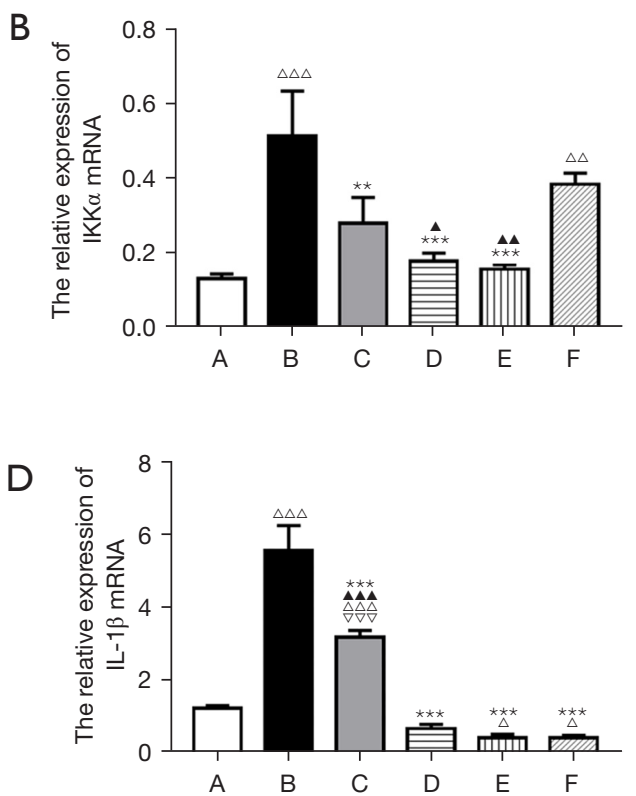

Figure 8 mRNA expression levels of IRAK-1, IKK $\alpha$, p65, and IL-1 $\beta$ in lung tissue proteins. A: Blank control; B: Model group; C: Positive control group; D: Low-dose TAF group; E: Middle-dose TAF group; F: High-dose TAF group. ${ }^{\Delta}, \mathrm{P}<0.05,{ }^{\Delta}, \mathrm{P}<0.01,{ }^{\Delta} \Delta \Delta, \mathrm{P}<0.001$, compared with the blank group; * $\mathrm{P}<0.05,{ }^{* *}, \mathrm{P}<0.01$, ${ }^{* * *}, \mathrm{P}<0.001$, compared with the model group; ${ }^{\mathbf{\Delta}}, \mathrm{P}<0.05,{ }^{\boldsymbol{\Delta}}, \mathrm{P}<0.01,{ }^{\mathbf{\Delta}}{ }^{*}, \mathrm{P}<0.001$, compared with the positive control group; ${ }^{\nabla}, \mathrm{P}<0.05,{ }^{\nabla \nabla}, \mathrm{P}<0.01,{ }^{\nabla \nabla}, \mathrm{P}<0.001$, compared with the high-dose group. TAF, total flavonoids of Trollius altaicus.

differences $(\mathrm{P}<0.001)$. Compared with the model group, all TAF groups played a significant role in reducing the expressions of IRAK-1, IKK $\alpha$, p65, and IL-1 $\beta$ mRNA. Among them, TAF had the most significant downregulation effect on IKK $\alpha$, and the effects on both middle- and highdose groups were significantly better than that on the positive control group $(\mathrm{P}<0.05$ and $\mathrm{P}<0.01$, respectively) (Table 10 and Figure 8).

\section{Discussion}

This study was conducted to explore the role of TAF in the 
pathogenesis of COPD under normal conditions by taking the normal body as the starting point and the incidence of COPD as the endpoint, and to judge the preventive role of TAF in the pathogenesis of COPD. Risk factors based on COPD are divided into individual susceptibility factors and environmental factors, among which, smoking and bacteria are the main factors. Therefore, we selected combined exposure to CS and LPS to build a stable COPD model (28).

In combination with animal research ethics and diagnostic procedures for patients with COPD, we performed non-invasive lung function tests and $\mathrm{X}$-ray examination to compare lung differences among the groups. The anti-inflammatory effect of TAF was determined by comparing the total blood cell count and inflammatory cytokines. Subsequently, the anti-inflammatory mechanism was determined by the inflammatory-related protein and its Mrna (29,30).

At present, tracheotomy after anaesthesia for lung function detection is a commonly used method; however, this procedure requires manual surgery, and setting of the forced vital capacity and has caused artificial damage to animals, which may affect subsequent experiments $(31,32)$. Therefore, the method selected in this study was to obtain relatively complete lung function and inflammatory indicators under a non-stress state to ensure animal safety as far as possible, and to better conform to human detection status.

Airway inflammation is a persistent state in the lungs of patients with COPD, which exists in the early and middle stages of COPD. Inflammation is aggravated in the acute inflammatory stage and will not completely disappear in the stable stage (33). Our experiment was designed to investigate the anti-inflammatory effect of TAF, and the results were as follows:

(I) Regarding the general characteristics, the therapeutic effect of the positive control group had a significant effect on the reduction of respiratory secretions, but not on improving mental status. In addition, the respiratory secretions and mental status of each TAF group significantly improved with increasing drug concentrations $(\mathrm{P}=0.000)$.

(II) With respect to changes in pulmonary function, compared with the blank control group, f, Penh, and PAU were significantly increased $(\mathrm{P}<0.01)$ and the TVb, Ti, Te, maximum PIF, and maximum PEF were markedly decreased $(\mathrm{P}<0.01)$ in the model group. Compared with the model group, TVb, Ti, Te, PIF, and PEF were notably increased, and Penh and PAU were significantly decreased in the positive control group $(\mathrm{P}<0.01)$. The downregulation of $\mathrm{f}, \mathrm{Penh}$, and PAU in each TAF group was significantly decreased, the downregulation of $\mathrm{f}$ increased with increasing TAF concentrations, and the downregulation results were better than those of the positive control group $(\mathrm{P}<0.05)$. TVb, Ti, Te, PIF, and PEF were significantly upregulated in each TAF group, among which the prolongation effects of $\mathrm{Ti}$ and $\mathrm{Te}$ were superior to that of the positive control group. $\mathrm{PIF}$ and PEF had a significant tendency to increase with increasing drug concentrations $(\mathrm{P}<0.01)$. In addition, the increased effect of PIF on the highdose group was similar to that of the positive control group, and the increased effect of PEF on the middle- and high-dose groups was better than that of the positive control group $(\mathrm{P}<0.01)$.

(III) In terms of pulmonary imaging changes, compared with the blank control group, the model group showed a noticeable increase in lung surface texture, pneumonia, and moderate emphysema. Compared with the model group, the positive control group showed moderate emphysema and increased lung surface texture, and the symptoms did not improve with treatment. The low-dose group showed mild emphysema, the middle-dose group showed only increased lung surface texture, and the high-dose TAF group showed relatively clear and bright lung fields.

(IV) In terms of changes in blood cell counts, the differences in WBC, LYM, and EOS counts among the groups were statistically significant ( $\mathrm{P}=0.000, \mathrm{P}=0.000$ and $\mathrm{P}=0.001$, respectively). A downregulation trend was found in the $\mathrm{N}$ and MON counts in each TAF group; however, the difference was not statistically significant compared to the other groups. The WBC, LYM and EOS counts were considerably higher in the model group than in the blank control group $(\mathrm{P}<0.01$, $\mathrm{P}<0.01$ and $\mathrm{P}<0.05$, respectively); however, the counts in the positive control group were markedly lower than those in the model group $(\mathrm{P}<0.01$, $\mathrm{P}<0.01$ and $\mathrm{P}<0.05$, respectively). Among the TAF groups, the downregulation of WBC, LYM, and EOS counts was most significant in the high-dose group $(\mathrm{P}<0.01)$, and the downregulation of LYM count was also notable in the middle-dose group 
$(\mathrm{P}<0.05)$. Although the downregulation trend of $\mathrm{N}$ and MON counts in each TAF group was not significant, the trend of the downregulation effect increased with increasing drug concentrations.

(V) Regarding lung histopathological changes, the W/ $\mathrm{D}$ values were significantly increased in the model and positive control groups compared with those in the blank control group $(\mathrm{P}<0.01)$. The W/D values of each TAF group decreased significantly with increasing drug concentration compared with the model and positive control groups $(\mathrm{P}<0.01)$. This finding suggests that TAF can effectively prevent the occurrence of pulmonary tissue oedema during COPD development. In the anatomical examination of the lung parenchyma, the surface of the lung parenchyma in the model group exhibited several black spots, the positive control group demonstrated scattered black patches, the low- and middle-dose groups had significantly reduced black spots, and the highdose group has lung parenchymal surface similar to that of the blank control group. With HE staining, compared with the blank control group, the lung tissue of the model group exhibited interstitial focal inflammatory cell infiltration and interstitial fibrous hyperplasia, and the lung tissue of the positive control group exhibited small amounts of fibrous tissue hyperplasia and inflammatory cell infiltration; however, no other pathological changes were observed. In the examination of lung tissues, the low-dose group displayed mild fibrous tissue hyperplasia and inflammatory cell infiltration, the middle-dose group showed mild fibrous tissue hyperplasia, and the high-dose group did not exhibit abnormal changes. The pathological grading score indicated moderate inflammation, emphysema, and mucus secretion in the model group compared with the findings in the blank control group $(\mathrm{P}<0.01)$. Compared with the model group, the positive control group had mild inflammation and emphysema, as well as very severe mucus secretion $(\mathrm{P}<0.01)$. The inflammation, emphysema and mucus secretion in each TAF group became mild with increasing drug concentrations, and the differences were statistically significant $(\mathrm{P}=0.002, \mathrm{P}=0.000$ and $\mathrm{P}=0.001$, respectively), suggesting that middledose TAF can effectively improve emphysema in
COPD development and that high-dose TAF can effectively prevent the occurrence of inflammation, lung emphysema, and mucus secretion.

(VI) Regarding inflammatory cell alterations, changes in inflammatory factor levels in the BALF revealed that IL-1 $\beta$, IL-6, IL-8, TNF- $\alpha$, and TGF- $1 \beta$ were significantly elevated in the model group; however, IL-10 was significantly downregulated $(\mathrm{P}<0.001)$. TAF had a significant downregulation effect on IL$1 \beta$, IL-6, IL-8, TNF- $\alpha$, and TGF- $1 \beta$ and induced IL-10 production in an injured organism, in which the high-dose group had a better effect than the positive control group $(\mathrm{P}<0.001)$.

(VII) For the alteration of protein expression in lung tissues, western blot results revealed that the protein bands of TLR4, IKK $\alpha, \mathrm{p} 65$, and IL- $1 \beta$ in the model group had significantly increased grey-scale values, suggesting that inflammation prompted the activation of these proteins $(\mathrm{P}<0.001)$. Increasing TAF concentrations had a significant effect on the activation of TLR4, IKK $\alpha, \mathrm{p} 65$, and IL-1 $\beta$. Increasing TAF concentrations positively inhibited the activation of IKK $\alpha$, p65, and IL-1 $\beta$, and this inhibition was most significant in the highdose group $(\mathrm{P}<0.001)$.

(VIII) Regarding lung tissue protein-related mRNA expression, the $\mathrm{qRT}-\mathrm{PCR}$ results revealed that IRAK-1, IKK $\alpha$, p 65 , and IL- $1 \beta$ mRNA expressions were significantly higher in the model group $(\mathrm{P}<0.001)$, and each TAF concentration effectively reduced the expression of IRAK-1, IKK $\alpha$, p65, and IL-1 $\beta$ mRNA expression and had the most significant downregulation effect on $\operatorname{IKK} \alpha(\mathrm{P}<0.001)$.

The study findings indicate that the positive control + model group has significant therapeutic effects on respiratory secretions, WBC count, LYM count, EOS count, and mucus secretion in lung tissues, but does not significantly improve substantial lesions during COPD development. TAF can delay the progression of lung parenchymal lesions and has a significant anti-inflammatory effect on the modelling process. Dexamethasone may be a good treatment choice for COPD. However, TAF may be a good medicinal material for preventing COPD occurrence and development in healthy people because of external environment and personal factors. Studies have demonstrated that in the COPD stable period, the levels of IL-1 $\beta$, IL-6, TNF- $\alpha$, and other inflammatory factors 
are higher than those in the normal period $(34,35)$. These pro-inflammatory factors are closely related to disease prognosis, and the stable disease stage is not an appropriate time to use hormone therapy; however, the medicinal value of TAF may help patients to improve this state.

Combined with the results of this study, our research group will continue to examine the deeper role of TAF in pneumonia, and conduct screening and related studies on other experimental findings to comprehensively determine the medicinal value of the Altai lotus flower.

\section{Acknowledgments}

Funding: This study was supported by the Key Laboratory Opening Project of Xinjiang Uygur Autonomous Region (No. 99-11091126606).

\section{Footnote}

Reporting Checklist: The authors have completed the ARRIVE reporting checklist. Available at https://atm. amegroups.com/article/view/10.21037/atm-22-331/rc

Data Sharing Statement: Available at https://atm.amegroups. com/article/view/10.21037/atm-22-331/dss

Conflicts of Interest: All authors have completed the ICMJE uniform disclosure form (available at https:// atm.amegroups.com/article/view/10.21037/atm-22-331/ coif). All authors report funding from the Key Laboratory Opening Project of Xinjiang Uygur Autonomous Region (No.99-11091126606). The authors have no other conflicts of interest to declare.

Ethical Statement: The authors are accountable for all aspects of the work in ensuring that questions related to the accuracy or integrity of any part of the work are appropriately investigated and resolved. The use of experimental animals in this study was approved by the Ethics Committee of Xinjiang Medical University (IACUC-20210106-16), in compliance with guidelines of Xinjiang Medical University for the care and use of animals.

Open Access Statement: This is an Open Access article distributed in accordance with the Creative Commons Attribution-NonCommercial-NoDerivs 4.0 International License (CC BY-NC-ND 4.0), which permits the noncommercial replication and distribution of the article with the strict proviso that no changes or edits are made and the original work is properly cited (including links to both the formal publication through the relevant DOI and the license). See: https://creativecommons.org/licenses/by-nc-nd/4.0/.

\section{References}

1. Wang C, Xu J, Yang L, et al. Prevalence and risk factors of chronic obstructive pulmonary disease in China (the China Pulmonary Health $[\mathrm{CPH}]$ study): a national cross-sectional study. Lancet 2018;391:1706-17.

2. Agustí A, Hogg JC. Update on the Pathogenesis of Chronic Obstructive Pulmonary Disease. N Engl J Med 2019;381:1248-56.

3. Wang XJ, Fang XY. Chronic Obstructive Pulmonary Disease Global Initiative 2019: An interpretation of the global strategy for the diagnosis, Treatment and prevention of chronic obstructive pulmonary Disease. Chinese General Practice 2019;22:2141-9.

4. Chen YH. GOLD 2020 Global Strategy for diagnosis, Treatment and Prevention of chronic obstructive pulmonary Disease: an interpretation. Chinese Journal of the Frontiers of Medical Science (Electronic Version) 2019;11:32-50.

5. Soriano JB, Polverino F, Cosio BG. What is early COPD and why is it important? Eur Respir J 2018;52:1801448.

6. Mehta M, Dhanjal DS, Satija S, et al. Advancing of Cellular Signaling Pathways in Respiratory Diseases Using Nanocarrier Based Drug Delivery Systems. Curr Pharm Des 2020;26:5380-92.

7. Blidberg K, Palmberg L, Dahlén B, et al. Chemokine release by neutrophils in chronic obstructive pulmonary disease. Innate Immun 2012;18:503-10.

8. El-Gazzar AG, Kamel MH, Elbahnasy OKM, et al. Prognostic value of platelet and neutrophil to lymphocyte ratio in COPD patients. Expert Rev Respir Med 2020;14:111-6.

9. Taniguchi K, Karin M. NF-kB, inflammation, immunity and cancer: coming of age. Nat Rev Immunol 2018;18:309-24.

10. Zhao XM. Compendium of Materia Medica. Beijing: Peoples Medical Publishing House, 1983:256.

11. Araújo VO, Andreotti CEL, Reis MP, et al. 90-Day Oral Toxicity Assessment of Tropaeolum majus L. in Rodents and Lagomorphs. J Med Food 2018;21:823-31.

12. Huo PF, Teng L, Li Q, et al. Separation and purification of the active components from The Flower of Altai By high speed countercurrent chromatography. Journal of Xinjiang Medical University 2017;40:1199-202. 
13. Huo P, Teng L, Hu X, et al. Extraction of Polygonum Orientale 2"-O- $\beta$-L-galactoside from Polygonum altai flower. Herald of Medicine 2018;37:869-73.

14. Wang B, You SH P, Xu YL, et al. Effects of total flavonoids extract of Trollius altaicus on acute lung injury induced by lipopolysaccharide in rats. Chinese Journal of Toxicology 2019;33:264-9.

15. Liu T, Chen WL, You SH P, et al. Protective effect of Trollius altaicus extract on acute lung injury induced by PM2.5 in rats. Cancer • Aberration • Mutation 2019;31:22-8.

16. You SH P, Liu X, Esmaguri N, et al. Experimental study on antitussive, expectorant, anti-inflammatory and analgesic effects of total flavonoids extract of Trollius altaicus. Journal of Xinjiang Medical University 2019;42:462-6.

17. Ye QY, Ma L, Ye XY, et al. Effect of total flavones from Trollius altaicus on lung fibrosis induced by PM2.5 in rats. Journal of Toxicology 2020;34:119-25.

18. Yan L, Wu W, Tian S. Antibacterial and antibiofilm activities of Trollius altaicus C. A. Mey. On Streptococcus mutans. Microb Pathog 2020;149:104265.

19. Ye X, Qi X, Zhang S, et al. Experimental study on protective effects of total flavonoids extracted from Trollius altaicus Bunge on acute bronchial epithelial BEAS2B cell injury induced by PM2.5. Journal of Toxicology 2020;34:191-6.

20. Ma HM, Liu Q ZH, Lu L, et al. Research progress of animal model of chronic obstructive pulmonary disease. Practical Preventive Medicine 2019;26:1406-9.

21. Leberl M, Kratzer A, Taraseviciene-Stewart L. Tobacco smoke induced COPD/emphysema in the animal modelare we all on the same page? Front Physiol 2013;4:91.

22. Lu XF. The regulation mechanism of TCM sequential therapy based on TLR4/ NF- $\kappa \mathrm{B}$ signaling pathway on inflammatory response of "AECOPD-risk window" rats. Beijing University of Chinese Medicine, 2016.

23. Halpin DMG, Criner GJ, Papi A, et al. Global Initiative for the Diagnosis, Management, and Prevention of Chronic Obstructive Lung Disease. The 2020 GOLD Science Committee Report on COVID-19 and Chronic Obstructive Pulmonary Disease. Am J Respir Crit Care Med 2021;203:24-36.

24. Liu JD, Qiu WC, Li ZY, et al. Establishment of noninvasive lung function index in rats. Advances in Veterinary Medicine 2017;38:49-53.

25. Wang CY. Prevention and treatment of Liuwei Buqi capsule on lung qi deficiency syndrome of chronic obstructive pulmonary disease in rats and its mechanism. Hubei University of Chinese Medicine, 2014.

26. Bao JR. Therapeutic observation of Mongolian medicine Hariabri-16 on chronic obstructive pulmonary disease model. Chinese Journal of Ethnic Medicine 2016;22:51-2.

27. Yang WK, Kim SH, Jung IC, et al. Effects of Scutellaria baicalensis Extract on Cigarette Smoke-Induced Airway Inflammation in a Murine Model of Chronic Obstructive Pulmonary Disease. J Med Food 2019;22:87-96.

28. Corlateanu A, Mendez Y, Wang Y, et al. Chronic obstructive pulmonary disease and phenotypes: a state-ofthe-art. Pulmonology 2020;26:95-100.

29. Brill SA, Guerrero-Martin SM, Metcalf Pate KA. The Symbiotic Relationship Between Scientific Quality and Animal Research Ethics. ILAR J 2021;60:334-40.

30. Andersen Olaf Sparre. Editorial Practices, Scientific Impact, and Scientific Quality. J Gen Physiol 2008;131:1.

31. Clutton RE. An Anglocentric History of Anaesthetics and Analgesics in the Refinement of Animal Experiments. Animals (Basel) 2020;10:1933.

32. An ZY, Pang BS. Assessment of normal reference range of lung function of Wistar rats. Acta Laboratorium Animalis Scientia Sinica 2013;21:102-4.

33. Sohal SS, Ward C, Danial W, et al. Recent advances in understanding inflammation and remodeling in the airways in chronic obstructive pulmonary disease. Expert Rev Respir Med 2013;7:275-88.

34. Eltom S, Dale N, Raemdonck KR, et al. Respiratory infections cause the release of extracellular vesicles: implications in exacerbation of asthma/COPD. PLoS One 2014;9:e101087.

35. Crisafulli E, Menéndez R, Huerta A, et al. Systemic inflammatory pattern of patients with communityacquired pneumonia with and without COPD. Chest 2013;143:1009-17.

(English Language Editor: A. Kassem)

Cite this article as: Li Y, Zhao J, Shao H, Jia W, Su D, Liu T. Preventive effect of total flavonoids of Trollius altaicus on a chronic obstructive pulmonary disease rat model based on the TLR4/NF-кB pathway. Ann Transl Med 2022;10(4):222. doi: 10.21037/atm-22-331 